\title{
ANALYSIS OF AFFORDABILITY OF MEAT, CHICKEN, FISH OR VEGETARIAN EQUIVALENT EVERY SECOND DAY IN HOUSEHOLDS IN LATVIA
}

\author{
Biruta Sloka ${ }^{1}$, Dr.oec, prof.; Inga Jekabsone ${ }^{2}$, Dr.sc.admin. \\ 1,2 University of Latvia
}

\begin{abstract}
In recent years, there are growing research and policy discussions on assessment and analysis of poverty and measurement of material conditions. Researchers and policy makers develop different set of indicators that describes material deprivation. Material deprivation that is usually defined as the extent of functioning failures in the dimension of material well-being is based on set of different items that refer to affordability of basic needs. Affordability of meat, chicken, fish or vegetarian equivalent every second day is one of main indicators that characterizes meeting the basic needs of the households.

In case of Latvia, macroeconomic indicators show that through recent years country is going on economic recovery path, however there are discussions on growing income inequality and poverty in regions.

Taking into account before mentioned, the aim of the paper is to analyse the material deprivation and food poverty by assessing the affordability of meat, chicken, fish or vegetarian equivalent every second day in households in Latvia.

The tasks are formulated as follows:

1) To review theoretical background on measuring the material deprivation and food poverty in households;

2) To assess empirical research on measuring the material deprivation and food poverty in households;

3) To analyse statistical data on households' affordability in Latvia.

In order to achieve the aim, following research methods have been used: scientific literature studies, statistical data analysis.

Main results and conclusions of the paper: there is wide range of indicators and indexes that measure food poverty and material deprivation. Based on these measures policy makers develop framework for social inclusion and inclusive society. In case of Latvia, analysis of affordability of on measuring the material deprivation and food poverty in households showed that there is positive trend over the years in regards to the share of people that cannot afford to meet their basic needs. However, the situation is rather critical in some regions of Latvia.
\end{abstract}

Key words: inclusive society, food poverty, material deprivation.

JEL code: I31, I32.

\section{Introduction}

Poverty is a complex issue, and a variety of approaches are required for its measurement and analysis. While monetary measures of income poverty are widespread, a long-standing tradition relies on non-monetary measures, based on either the respondent's self-assessment of their own conditions or on measures of ownership of consumer goods and living standards. Measures of material deprivation fall into this latter category. These measures rest on shared judgments about which items are more important to provide a "decent" living standard, irrespective of people's preferences and of their capacity to afford these items. Material deprivation is typically the outcome of income poverty when this persists over time, or when individuals experience repeated spells of it. Because of this, measures of material deprivation add important information to that provided by conventional income measures, permitting an assessment of poverty from a longer-run perspective and furthering understanding of the causal mechanisms at work (Boarini and d'Ercole, 2006).

Food poverty is one way how to research poverty and deprivation. Food poverty has emerged as a social policy concern in many countries in the last decade (Purdy et al., 2006; Carney and Maitre, 2012).

\footnotetext{
biruta.sloka@lu.Iv

2 jekabsone_inga@inbox.Iv
} 
In case of Latvia, there are discussions on growing income inequality and poverty in regions despite the positive trends of macroeconomic indicators. Thereby, the assessment of material deprivation and food poverty is needed.

The hypothesis of the research: despite that overall share of households in Latvia experiencing severe material deprivation decreases, it is significant in some regions in Latvia.

The aim of the paper is to analyse the material deprivation and food poverty by assessing the affordability of meat, chicken, fish or vegetarian equivalent every second day in households in Latvia.

The tasks are formulated as follows:

1) To review theoretical background on measuring the material deprivation and food poverty in households;

2) To assess empirical research on measuring the material deprivation and food poverty in households;

3) To analyse statistical data on households' affordability in Latvia.

In order to achieve the aim, following research methods have been used: scientific literature studies, statistical data analysis.

Novelty and topicality of the research: measurement of material deprivation and food poverty is topical issue in context of policy making for overall poverty reduction. Affordability of meat, chicken, fish or vegetarian equivalent every second day is one of fundamental indicators to assess material deprivation. In case of Latvia, it is important to analyse material deprivation in context of demographic and socio-economic profile of households in order to provide policy recommendations.

\section{Problematic questions of the conducted research:}

1) According to the latest research developments, what is the best practice to measure material deprivation and food poverty?

2) What is the demographic and socio-economic profile of poor households in Latvia?

3) What is the situation in regions of Latvia in context of material deprivation and food poverty?

During the research, following information sources were used: scientific literature, published empirical studies, statistical data.

Delimitations of research subjects: taking into account that there are different measures on the material deprivation and food poverty, main focus will be on indicator "Affordability of meat, chicken, fish or vegetarian equivalent every second day in households" in Latvia.

\section{Theoretical discussion}

Food poverty is defined as the inability to have an adequate and nutritious diet due to issues of affordability or accessibility (Dowler, 1998). Several researchers (Friel and Conlon, 2004; Hjelm et al., 2016) for measuring poverty for food security analysis are using consumption - versus assetbased approaches expand this definition to include the social and cultural participatory aspect of food poverty. According to the latest research (Carney and Maitre, 2012), aspects of poverty effects of food price escalation and mitigation options (Solaymani et al., 2017), the elements of food poverty definition encompass affordability, access and social participation.

There are different approaches how to research food poverty. The Vincentian Partnership for Social Justice (VPSJ) (Collins et al., 2012) found, in its 2012 study on a minimum income standard, that the weekly cost of food is the most expensive area of expenditure for most of the nine household types examined. It was particularly expensive for households with children, and pensioners, and for lone parent households, the cost of food was only exceeded by childcare costs. Additionally, in their study on minimum essential budgets for households in rural areas, the VPSJ also found that there 
were considerable differences in the costs of food between urban and rural locations (Mac Mahon et al., 2010). Davis et al. (2012) found that the income of households in the UK who were benefits recipients, and minimum wage earners, did not meet the minimum income standard required by these households. The minimum income standard was based on the costs of food, clothing, housing as well as participating in society in Britain.

Other approaches to researching food poverty have focused on the nutritional consumption of low income and deprived groups, and the relationship of this with health, e.g. Friel and Conlon (2004) found that people in lower social classes (semi-skilled and unskilled) consumed unhealthier food products. Research by Dowler and O'Connor (2012) highlighted the relationship between poverty, food and health inequalities. They discuss the prevalence of cheap unhealthy foods consumed by lower socio-economic groups contributing to poor nutritional outcomes and the failure of anti-poverty policies to include food and nutritional needs.

Researchers have defined different indicators that measure food poverty. E.g. Review of the National Taskforce on Obesity (DOHC, 2009) defined four indicators:

1) Inability to afford a meal with meat or vegetarian equivalent every second day;

2) Inability to afford a roast or vegetarian equivalent once a week;

3) Whether during the last fortnight, there was at least one day (i.e. from getting up to going to bed) when the respondent did not have a substantial meal due to lack of money;

4) Inability to have family or friends for a meal or drink once a month.

Several studies (Bellani, 2013; Bossert et al., 2013, Borsh-Supan et al., 2015) assess deprivation relying on the recognition that deprivation is a multifaceted state that can be properly described by taking into account several aspects of individuals' quality of life, including but not limited to financial outcomes. Borsh-Supan et al. (2015) offer to measure material deprivation covering different aspects of economic circumstances by asking respondents question on affordability to cover costs for meat, fruit, groceries, holiday, unexpected expenses, clothing, shoes, heating, glasses, dentist and doctor. Questions are formulated as follows:

- Can your household afford to regularly buy necessary groceries and household supplies?

- You do not eat meat, fish of chicken more often [than three times per week] because: you cannot afford to eat it more often;

- Could your household afford to pay an unexpected expense without borrowing any money? Researchers also indicated strong correlation between subjective assessment of material conditions (additional information provided by the households apart from the questions) and the deprivation items (Borsh-Supan et al., 2015), some countries have several approaches in this aspect (Healy, 2019).

\section{Research results and discussion}

Since 2014, Eurostat disseminates early results for severe material deprivation rates. According to Eurostat, the severe material deprivation rate represents the proportion of people living in households that cannot afford at least four of the following nine items:

- mortgage or rent payments, utility bills, hire purchase instalments or other loan payments;

- one week's holiday away from home;

- a meal with meat, chicken, fish or vegetarian equivalent every second day;

- unexpected financial expenses;

- a telephone (including mobile telephone); 
- a colour TV;

- a washing machine;

- a car; and

- heating to keep the home adequately warm (Eurostat, 2018).

Since 2013, the rate of severe material deprivation in the EU-28 decreased from $9.6 \%$ to $6.7 \%$, i.e. by 2.9 percentage points (pp). One of largest decrease in the proportion of persons lacking resources was Latvia (-12.7 pp between 2013 and 2017), reflecting the improving material living conditions in those countries (Eurostat, 2018).

Eurostat analysts concluded that the early data for 2017 show that severe material deprivation rates are determined mainly by changes in the ability to afford:

- unexpected financial expenses;

- a meal with meat, chicken or fish (or vegetarian equivalent) every second day; and

- one week's holiday away from home (Eurostat, 2018).

In case of Latvia, the percentage of people who said they were unable to face unexpected expenses fell, compared with the 2014 data, decreased by 7.5 pp. The early data for 2017 show that the percentage of the population that cannot afford to go on a week's annual holiday slightly increased in Latvia (+0.2 pp). The percentage of people in Latvia who said in 2017 they could not afford a meal with meat, fish, chicken or a vegetarian equivalent every second day decreased year on year (in $2014-18 \%$, in $2017-13 \%$ ). In comparison, the average level of this indicator in EU is $7.9 \%$, while in Lithuania it is $16.5 \%$, Estonia - $5.3 \%$, Sweden - $1.8 \%$ (Eurostat, 2018).

Further analysis will be on indicator "Affordability of meal with meat, chicken or fish (or vegetarian equivalent) every second day" in Latvia.

Data show that overall tendency on population ability to afford a meal with meat, chicken of fish (or vegetarian) equivalent every second day is increasing (Fig. 1). The economic crises (2009-2011) affected affordability of households - in 201130.9 \% of all population or 56.6 \% of population below the risk of poverty threshold could not afford a meal with meat, chicken or fish (or vegetarian equivalent) every second day.

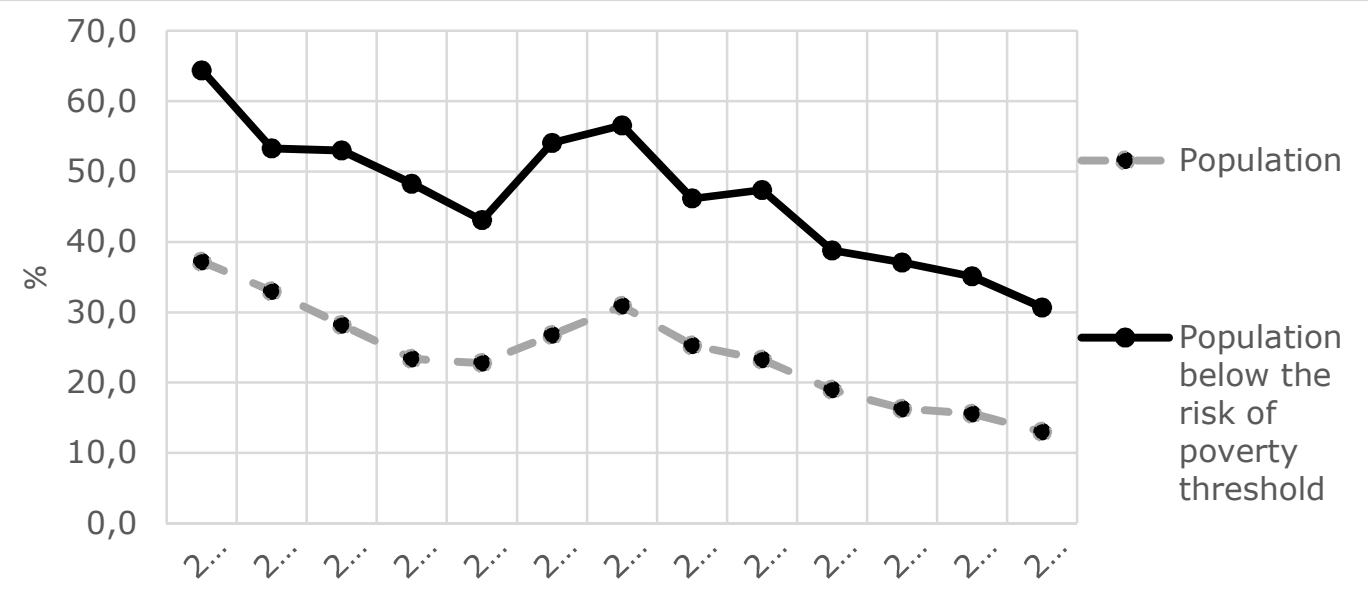

Source: authors' construction based on data in databases of Central Statistical Bureau of Latvia, SILC

Fig. 1. Population unable to afford a meal with meat, fish, chicken or a vegetarian equivalent every second day, 2005-2017, \%

As it was mentioned before, the discussions over material deprivation in regions is topical. Also, in this case data show negative tendency. In 2017, the lowest share of population unable to afford meat, fish or chicken (or vegetarian equivalent) is in Riga - $7.9 \%$; in Pieriga region - $11 \%$ and in 
Zemgale region - $13.2 \%$, while in Vidzeme region it is $19.6 \%$, alike in Latgale region it is $18.4 \%$ and Kurzeme region - 18 \%. Statistics show that there are significant disparities between Riga \& Pieriga region and other regions (except Zemgale region).

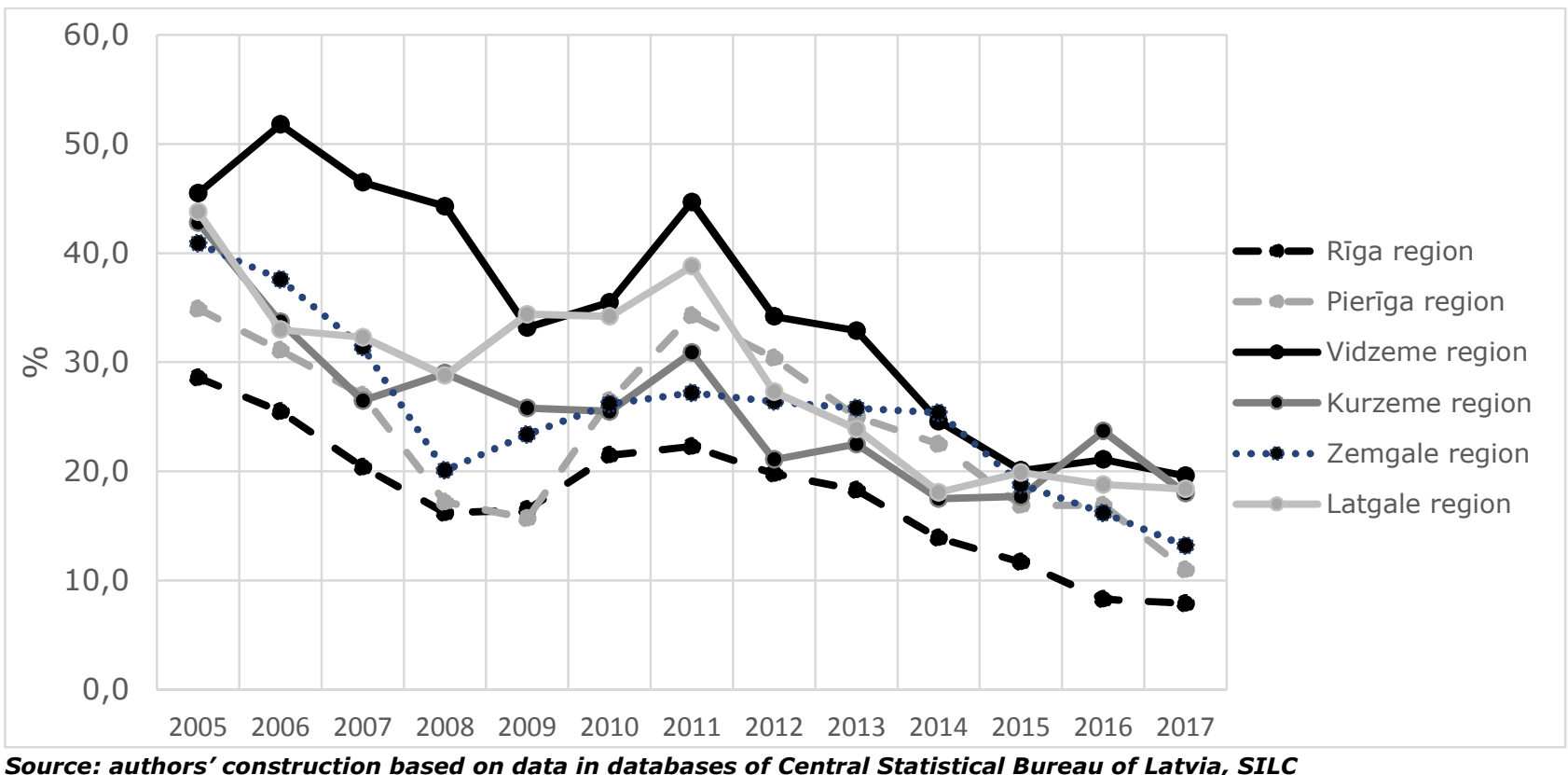

Source: authors' construction based on data in databases of Central Statistical Bureau of Latvia, SILC

Fig. 2. Population unable to afford a meal with meat, fish, chicken or a vegetarian equivalent every second day - regional dimension, 2005-2017, \%

In case of disparities in affordability of meal with meat, fish or chicken (or vegetarian equivalent) between urban and rural territories (Fig. 3), they are rather insignificant - in 2017, $11.4 \%$ of urban households admitted difficulties with affordability, while $16.5 \%$ of rural households.

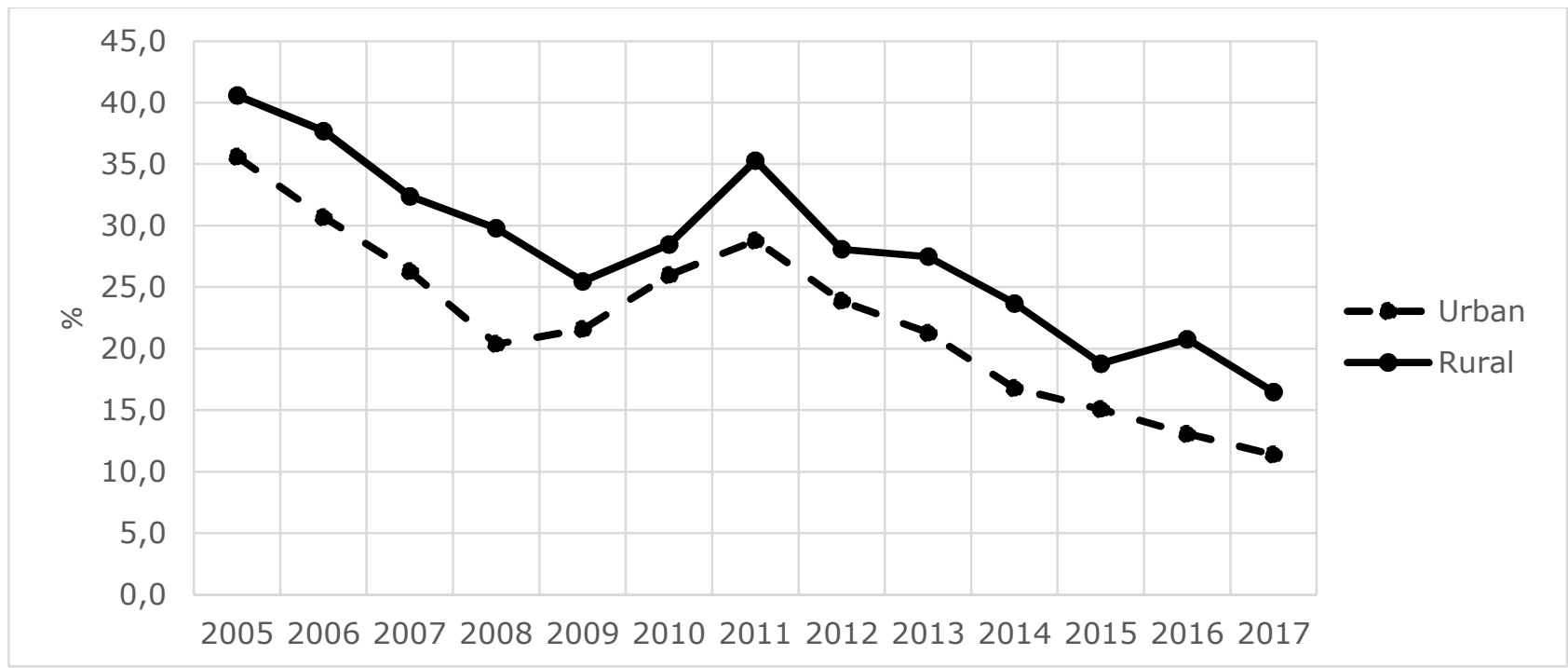

Source: authors' construction based on data in databases of Central Statistical Bureau of Latvia, SILC

Fig. 3. Population unable to afford a meal with meat, fish, chicken or a vegetarian equivalent every second day - urban and rural dimension, 2005-2017, \%

In addition, the analysis of households' structure was provided in context of affordability of a meal with meat, fish or chicken (or vegetarian equivalent) every second day (Fig. 4). Single person households aged $65+$ face with the greatest affordability difficulties $-43.4 \%$ of all households cannot afford proper meal. In the most favourable positions are couples with one child (15.3\%) and couples with two children (16.2\%). 


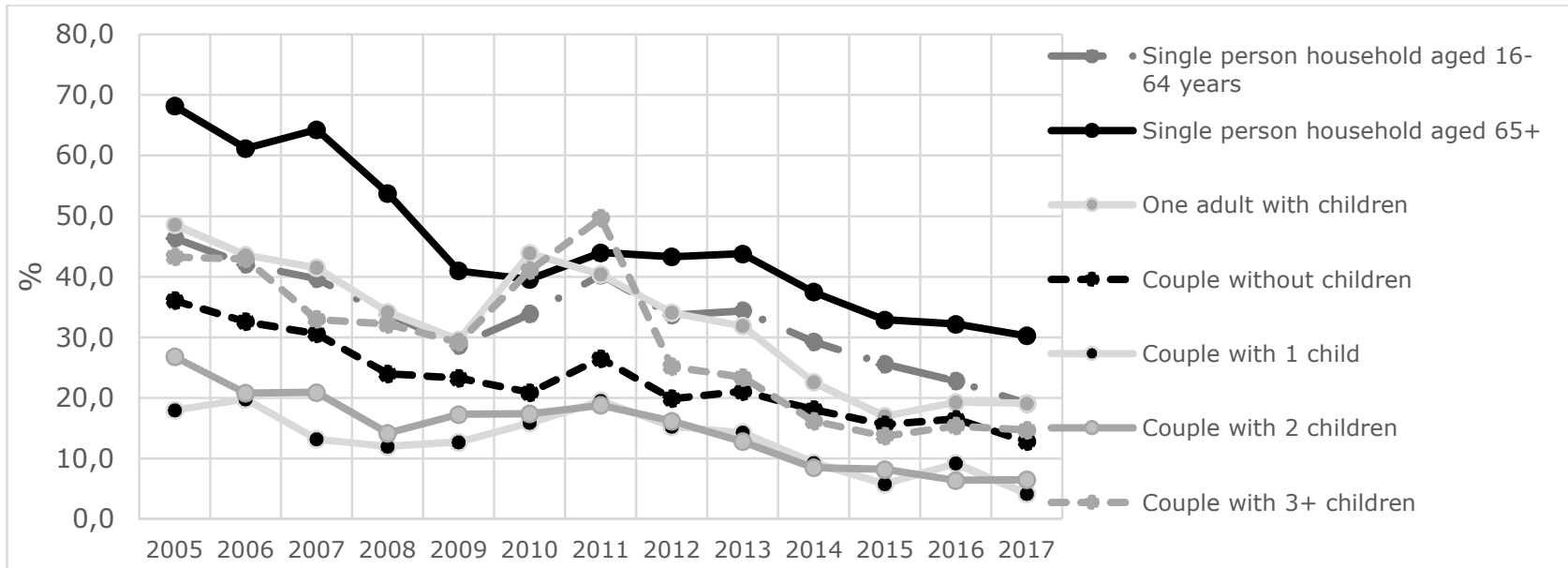

Source: authors' construction based on data in databases of Central Statistical Bureau of Latvia, SILC

Fig. 4. Population unable to afford a meal with meat, fish, chicken or a vegetarian equivalent every second day - household type, 2005-2017, \%

In context of education level, persons with higher education experiences less difficulties with affordability of proper meal - in 2017, $6 \%$ of persons admitted that they are unable to afford a meal with meat, fish or chicken (or vegetarian equivalent) every second day. While, this indicator for persons with secondary education is $13.9 \%$ and for persons with basic education - $26.1 \%$ (Fig. 5). It proves that education level strongly correlates with the affordability of proper meal.

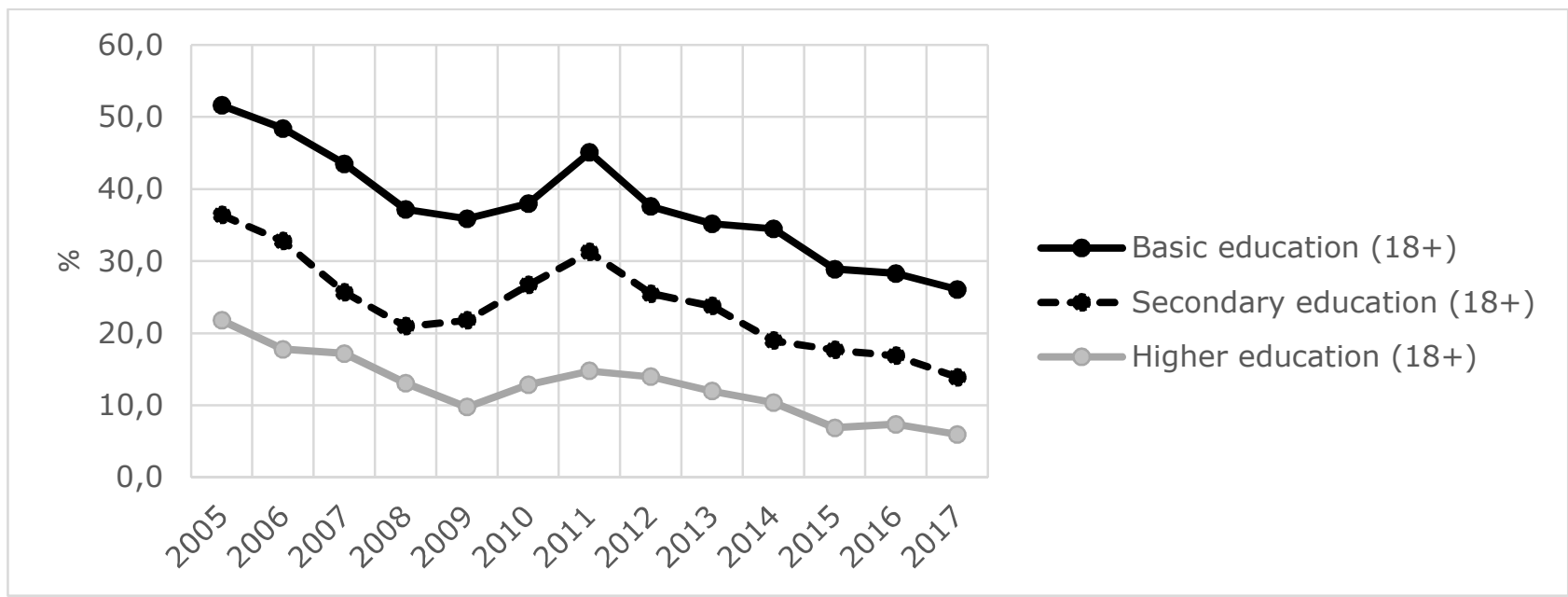

Source: authors' construction based on data in databases of Central Statistical Bureau of Latvia, SILC

Fig. 5. Population unable to afford a meal with meat, fish, chicken or a vegetarian equivalent every second day - education level, 2005-2017, \%

The research of material deprivation of households in Latvia by analysing indicator "Affordability of meal with meat, chicken or fish (or vegetarian equivalent) every second day" showed that over last years the overall level of affordability has increased. In addition, the regional perspective showed that there are significant disparities between Riga \& Pieriga region and other regions. However, there are No significant differences between urban and rural territories. Data demonstrated that single person households aged 65+ are the most at the risk of the food poverty, while couples with one child or two children are the least at risk. Analysis of educational level proved that education level strongly correlates with the affordability of proper meal.

\section{Conclusions, proposals, recommendations}

1) There are different approaches how to measure poverty. One of the research directions focuses on evaluation of material deprivation and food poverty. Indicator "Affordability of meal with meat, 
chicken or fish (or vegetarian equivalent) every second day" is one of the fundamental measures how to assess material deprivation and food poverty.

2) In case of Latvia, there is a positive tendency regarding affordability of households a meal with meat, chicken or fish (or vegetarian equivalent) - in 2017, $13 \%$ of population suffer from food poverty (for comparison, in 2011 the share was $30.9 \%$ ). However, it is still behind average level of EU $(7.9 \%)$.

3) Regarding regional aspect of food poverty, the analysis showed that there are significant differences between Riga \& Pieriga region and other regions - the share of households who suffers from food safety is almost two times bigger in Vidzeme, Latgale, Kurzeme than in Riga \& Pieriga region.

4) In addition, analysis showed that in urban territories affordability of proper meal is higher than in rural territories, however these changes are rather insignificant.

5) During the research, it was proved that seniors who live alone are at the most risk of food poverty, while couples with one or two children are in the most favourable position regarding material deprivation.

6) Analysis of statistical data demonstrated that more educated people suffer less from the food poverty - education level strongly correlates with the affordability of proper meal.

\section{The paper was supported by the project „INTERFRAME-LV"}

\section{Bibliography}

1. Bellani, L. (2013). Multidimensional Indices of deprivation: the Introduction of Reference Groups Weights. Journal of Economic Inequality, Volume 11, pp. 495-515.

2. Boarini, R., d'Ercole, M. (2006). Measures of Material Deprivation in OECD Countries. OECD Social, Employment and Migration Working Papers, No. 37, OECD Publishing, Paris.

3. Borsh-Supan, A., Kneip, T., Litvin, H., Myck, M., Weber, G. (2015). Ageing in Europe - Supporting Policies for an Inclusive Society. Walter de Gruyter $\mathrm{GmbH}$, Berlin/Boston, $392 \mathrm{p}$.

4. Bossert, W., Chakravarty, S., D'Ambrosio, C. (2013). Multidimenional Poverty and Material Deprivation with Discrete Data. Review of Income and Wealth, Volume 59, Issue 1, pp. 29-43.

5. Carney, C., Maître, B. (2012). Constructing a food poverty indicator for Ireland using the survey on income and living conditions. Social Inclusion Technical Paper No. 3, Dublin: Department of Social Protection. Retrieved:

https://www.lenus.ie/bitstream/handle/10147/251573/xFoodPovertyPaper.pdf?sequence=1\&isAllowed=y. Access: 14.02.2019.

6. Collins, M. L., Mac Mahon, D.C. B.,Weld, G., Thornton, R. (2012). A Minimum Income Standard for Ireland, a consensual budget standards study examining households types across the lifecycle. Dublin: The Policy Institute TCD Retrieved: https://www.tcd.ie/Communications/content/pdf/PolicyInstituteBP27Feb2012.pdf. Access: 03.02.2019.

7. Davies, A., Hirsch, D., Smith, N., Beckhelling, J., Padley, M. (2012). A Minimum Income Standard for the UK in 2012, Keeping up in Hard Times. York: Joseph Rowntree Foundation. Retrieved: http://www.jrf.org.uk/sites/files/jrf/minimum-income-standards-2012-full.pdf. Access: 01.02.2019.

8. Department of Health and Children (2009). Report of the Inter-sectoral Group on the Implementation of the Recommendations of the National Taskforce on Obesity. Dublin: Department of Health and Children. Retrieved: http://www.lenus.ie/hse/bitstream/10147/73033/1/report_group_ntfo.pdf. Access: 09.02.2019.

9. Dowler, E. (1998). Food Poverty and Food Policy. IDS Bulletin, Volume 29, Issue 1, pp. 58-65.

10. Dowler, E., O' Connor, D. (2012). Rights-based approaches to addressing food poverty and food insecurity in Ireland and UK, Social Science and Medicine, Volume 74, Issue 12, pp. 44-51.

11. Friel, S., Conlon, C. (2004). Food Poverty and Policy. Dublin: Combat Poverty Agency. Retrieved: http://www.combatpoverty.ie/publications/FoodPovertyAndPolicy_2004.pdf. Access: 09.02.2019.

12. Healy, A.E. (2019). Measuring Food Poverty in Ireland: The Importance of Including Exclusion. Irish Journal of Sociology, pp. 1-24.

13. Hjelm, L., Mathiassen, A., Wadhwa, A. (2016). Measuring Poverty for Food Security Analysis: ConsumptionVersus Asset-Based Approaches. Food and Nutrition Bulletin, Volume 37, Issue 3, pp.275-289.

14. MacMahon D.C., B., Weld, G.,d Thornton, R. (2010). Minimum Essential Budgets for Households in Rural Areas Six Household Types in Rural Areas, Dublin: Vincentian Partnership for Social Justice. Retrieved: http://www.budgeting.ie/images/stories/Publications/Minimum_Essential_Budgets_for_House holds_in_Rural_Areas.pdf. Access: 03.02.2019. 
15. Material Deprivation Statistics - Early Results (2018). Eurostat. Retrieved: https://ec.europa.eu/eurostat/statistics-explained/index.php/Material_deprivation_statistics__early_results. Access: 13.02.2019.

16. Purdy J., McFarlane G., Harvey H., Rugkasa J., Willis K. (2006). Food Poverty Fact or Fiction? Belfast: Public Health Alliance.

17. Solaymani, S., Yusma, N., Yusoff.M. (2017). Poverty Effects of Food Price Escalation and Mitigation Options: The Case of Malaysia. Journal of Asian and African Studies, Volume 53, Issue 5, pp. 685-702. 